\title{
Marcos legais da propaganda de medicamentos: avanços e retrocessos
}

I ${ }^{1}$ Carolina Pires Araújo, ${ }^{2}$ Rosany Bochner, ${ }^{3}$ Álvaro César Nascimento I

Resumo: Desde o início da civilização brasileira,

\author{
1 Mestrado em Informação e \\ Comunicação em Saúde pela \\ Fiocruz. Endereço eletrônico: \\ carolpa_com@yahoo.com.br. \\ ${ }^{2}$ Doutora em Saúde Pública \\ (Ensp/Fiocruz), pesquisadora \\ do Laboratório de Informação \\ Científica e Tecnológica \\ em Saúde (ICICT/Fiocruz) e \\ professora do Programa de Pós- \\ Graduação em Informação e \\ Comunicação em Saúde (ICICT/ \\ Fiocruz). Endereço eletrônico: \\ rosany@icict.fiocruz.br.

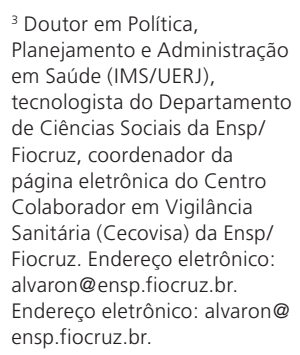
em Saúde (IMS/UERJ), tecnologista do Departamento de Ciências Sociais da Ensp/ Fiocruz, coordenador da página eletrônica do Centro Colaborador em Vigilância Sanitária (Cecovisa) da Ensp/ Fiocruz. Endereço eletrônico: alvaron@ensp.fiocruz.br. Endereço eletrônico: alvaron@ ensp.fiocruz.br. Higiene (1851), a Lei de Vigilância Sanitária (1976)
e a criação da ANVISA (1999). Identificou-se que os marcos acompanham o contexto estrutural do país, contribuindo para a consolidação do campo da regulação hoje.

> Palavras-chave: publicidade de medicamentos; vigilância sanitária; história. 


\section{Introdução}

No século XXI, em meio ao avanço tecnológico e científico sem precedentes, a sociedade não fica isenta de transformações no campo social, nas suas diversas formas de relações socioculturais. $\mathrm{Na}$ esfera da saúde coletiva, o fenômeno da medicalização (BARROS, 1995) ganha destaque no debate público, à medida que oferece riscos à população. Sendo uma ponte entre o consumidor e a indústria, intermediada pelos aparatos de comunicação midiática, a promoção comercial de medicamentos se insere nesse processo e tem sua contribuição no estímulo ao consumo inadequado desses e de outros produtos para a saúde.

A exploração do valor simbólico do medicamento - socialmente sustentado pela indústria farmacêutica, agências de publicidade e empresas de comunicação - passa a representar um dos mais poderosos instrumentos para a indução e fortalecimento de hábitos voltados para o aumento do consumo (NASCIMENTO, 2005, p. 22).

A propaganda é uma ferramenta legítima, utilizada por instituições diversas na divulgação de produtos, conceitos e ideias; "geralmente trabalha para construir fidelidade à marca” (KOTLER; KELLER, 2006, p. 585). Pode-se afirmar, assim, que a publicidade não constitui um problema se os objetivos comerciais não ultrapassam os limites éticos. A grande discussão parece estar no papel do marketing da indústria farmacêutica, o qual, com seus valores altíssimos, é considerado abusivo por muitos pesquisadores.

A partir dessa perspectiva, não é difícil notar que a propaganda de medicamentos, enquanto estratégia persuasiva, pode representar risco sanitário, caso não se comprometa com a divulgação de informação correta e segura. Nesse sentido, várias são as tentativas de controle sanitário por parte do Estado, as quais parecem se consolidar em embates de domínio ético e legal. Em busca de compreender o contexto que norteia a atual conjuntura da problemática sobre propaganda de medicamentos, o presente estudo irá traçar um percurso histórico, a partir dos principais marcos legais. É válido destacar que a proposta é apenas sistematizar os marcos da regulação e promover discussōes acerca das questōes apresentadas; não se trata, portanto, de um artigo de investigação.

\section{Breve histórico: do império aos anos 60 do século XX}

A arte de propagar é tão antiga quanto a própria oratória. Desde os remotos tempos dos sofistas, já se propagavam ideias com finalidade persuasiva e comercial. Com o 
desenvolvimento dos meios de comunicação de massa, assiste-se a um processo de intensificação na propagação comercial de produtos ou serviços. No Brasil, durante o Império, já se tem registro de anúncios relacionados a produtos terapêuticos. À época, o Jornal do Commercio, fundado em 1827 e considerado um dos mais importantes periódicos da história do Brasil, passou a publicar os anúncios de medicamentos em larga escala. Em função da precariedade das condições sanitárias, o Ministério do Império decide criar, 23 anos mais tarde, uma Comissão Central de Saúde Pública, a qual originou a Junta Central de Higiene, que pode ser considerada como os primórdios de uma regulação sanitária.

Com a Proclamação da República, alguns episódios marcaram a história, como a Revolta da Vacina, em 1904, e a Gripe Espanhola, em 1918. Em 1923, foi emitido o Decreto no 16.300 (BRASIL, 1923), intitulado "Regulamento Sanitário Federal", sendo conhecido como "Reforma Chagas", o qual apontava para um novo panorama da regulação sanitária. Mas somente em 1931, com o Decreto de $n^{\circ} 20.377$ (BRASIL, 1931), que regulamentava a profissão do farmacêutico, eram introduzidas as primeiras restrições legais para anúncios de medicamentos.

Foi apenas o início, e um tanto tímido, do controle sobre a propaganda de medicamentos, porque, no alvorecer da década de 30, começou a ficar claro que se tornara inadiável a tarefa de fiscalizar e regulamentar um mercado no qual, para ficar apenas em um exemplo, uma substância como a cocaína era anunciada como se fosse um composto banal, prescrita, inclusive, para crianças (BUENO; TAITELBAUM, 2008, p. 72).

Nesse mesmo período, o rádio consolida-se como um importante veículo de comunicação para a época, sendo regulamentado pelo Governo Vargas, quando autorizou, por meio do Decreto-lei de no 21.111 (BRASIL, 1932), o uso da propaganda nessa mídia. A Rádio Nacional, uma das estações de maior prestígio na época, surge em 1936. Nesse momento, dentre os principais anunciantes, destacavam-se os produtos do laboratório Sidney Ross - entre eles o Sonrisal, além do Colírio Moura Brasil, Elixir de Inhame e Urudonal (BUENO; TAITELBAUM, 2008, p. 75).

A partir de então, busca-se controlar a propaganda de medicamentos sob o ponto de vista ético. Ainda no governo de Getúlio Vargas, é implantado o Decreto-lei no 4.113 (BRASIL, 1942), o qual regulamentava a publicidade para os profissionais e instituições de saúde, tais como médicos, dentistas, parteiras, massagistas, enfermeiros, casas de saúde e estabelecimentos congêneres. 
A década de 50 impõe uma nova forma de comunicação, com o surgimento da televisão, que se consolidará como a mídia mais popular no fim do século XX. Já no governo de Juscelino Kubitschek, ocorre o primeiro Congresso Brasileiro de Publicidade, promovido pela Associação Brasileira das Agências de Publicidade (Abap), em outubro de 1957, sendo elaborado o Código de Ética Publicitária (BRASIL, 1957), cujas normas e recomendações aos profissionais da área foram compiladas. Nos anos 60, vivenciou-se um intenso debate entre o Estado e as indústrias farmacêuticas no que tange à vigilância sanitária.

Figura 1. Cenário estrutural relativo ao controle da propaganda de medicamentos.

\begin{tabular}{|c|c|c|c|}
\hline \multirow[b]{2}{*}{ 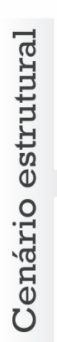 } & 8 & 9 & 9 \\
\hline & $\begin{array}{l}1851 \\
\text { - Criação da Comissão } \\
\text { Central de Saúde Pública, a } \\
\text { qual deu origem a Junta } \\
\text { Central de Higiene. }\end{array}$ & $\begin{array}{l}1931 \\
\text { - Decreto n 20.37 7: } \\
\text { regulamentava a profissão } \\
\text { d o farma c ê utico, } \\
\text { introduzindo as primeiras } \\
\text { restrições legais para } \\
\text { a n u } \mathrm{n} \text { i o s d e } \\
\text { medicamentos. }\end{array}$ & $\begin{array}{l}1942 \\
\text { - Decreto-lei n } n^{\circ} .113 \text { : } \\
\text { regu lam e n ta va a } \\
\text { propaganda para médicos, } \\
\text { dentistas, parteiras, } \\
\text { massagistas, enfermeiros, } \\
\text { casas de saúde e } \\
\text { estabelecimentos } \\
\text { congêneres. }\end{array}$ \\
\hline
\end{tabular}

\section{Lei de Vigilância Sanitária: marco na regulamentação}

Esse breve histórico elucida um pouco o delinear da regulação sanitária no país, responsável em grande medida pela consolidação da estrutura do campo tal como se configura hoje (Figura 1). Para Rozenfeld (1998, p. 238), por mais que o registro e a fiscalização de medicamentos existam desde a época do Brasil colônia, o campo estrutura-se de fato somente na década de 70. Um marco conjuntural é a Lei de Vigilância Sanitária, ainda vigente, e que se situa num importante período de desenvolvimento econômico no Brasil.

É possível dizer que, nos anos 70, o Brasil viveu um dos períodos mais controversos de sua história. Se, por um lado, era um momento de crescimento econômico sem precedentes, por outro, o país presenciava o medo e o caos de uma nação sob regime de ditadura militar. Pode-se afirmar que é nessa época que a classe média se consolida no país, com forte potencial para movimentar a economia. 
Sob a égide do "milagre econômico", assiste-se à formação do complexo médico-industrial, já que a década de 70, conforme aponta Temporão, foi marcada por um crescimento expressivo na área da produção científica da saúde coletiva, que se deu pela incorporação a vários estudos do instrumental das ciências sociais (1983, p. 13). Por outro lado, embora a economia estivesse forte, o setor da saúde se encontrava em condições precárias. Era a grande oportunidade para a indústria da saúde crescer de forma vertiginosa. "O país não tinha planejamento familiar, mas pílulas anticoncepcionais vendiam como se fossem guloseimas. Já as pílulas antirressaca eram vendidas como se fossem pílulas... anticoncepcionais” (BUENO; TAITELBAUM, 2008, p. 117). Vale destacar que, nesse momento, a televisão já se consolidava como o meio de comunicação mais popular da história, com abrangência em praticamente todo o território nacional, o que contribuía para a promoção comercial indiscriminada por meio dessa mídia.

Em sua tese de doutorado, Lucchese (2008) fez uma síntese histórica da vigilância sanitária e classificou o período de 1940 a 1990 como modelo de substituição de importações, mencionando que, nesse momento, houve maior preocupação com o controle dos produtos de interesse sanitário. Nessa época, a participação da indústria no Produto Interno Bruto chegou a superar a da agricultura, sendo desenvolvida uma produção variada em larga escala de mercadorias sob controle sanitário, predominando empresas transnacionais (2008, p. 56). É nesse contexto que se institui a Lei de Vigilância Sanitária (BRASIL, 1976), que contou com dois antecedentes legais importantes para a sua criação, como mostra a Tabela 1 .

Tabela 1. Antecedentes da Lei de Vigilância Sanitária.

\begin{tabular}{|l|l|}
\hline Ano & Lei \\
\hline 1971 & $\begin{array}{l}\text { Decreto no 68.806 (BRASIL, 1971): criou a Central de Medicamentos } \\
\text { (Ceme), instituída como órgão da Presidência da República, para regular a } \\
\text { produção e a distribuição de medicamentos dos laboratórios farmacêuticos } \\
\text { vinculados a ministérios. }\end{array}$ \\
\hline 1973 & $\begin{array}{l}\text { Decreto no } 72.552 \text { (BRASIL, 1973): oficializou o Plano Diretor de } \\
\text { Medicamentos, que passou a orientar as ações da Ceme. }\end{array}$ \\
\hline
\end{tabular}


A Lei de no 6.360, assinada em 23 de setembro de 1976 no Governo Geisel, ficou conhecida como a Lei de Vigilância Sanitária, e também contribuiu para reforçar as exigências legais nas mais diversas áreas da vigilância sanitária, inclusive no tópico propaganda de medicamentos. Ela inaugura, assim, uma importante mudança no controle sanitário, uma vez que o decreto de 1931 não tinha efeito prático. Como forma de regulamentá-la, foi instituído, no ano seguinte, o Decreto de no 79.094 (BRASIL, 1977).

A legislação introduziu pontos importantes, como a necessidade de autorização prévia pelo Ministério da Saúde dos anúncios de produtos sujeitos à vigilância sanitária, e a proibição de propaganda de medicamentos de venda sob prescrição para o consumidor comum, sendo somente permitida se direcionada aos profissionais de saúde. Um ponto de destaque nessa lei é que ela cria a Secretaria Nacional de Vigilância Sanitária (SNVS) .

No início do Governo Collor, entra em vigor a Lei de no 8.078/90 (BRASIL, 1990), conhecida como Código de Defesa do Consumidor (CDC), um importante avanço na defesa dos interesses dos consumidores, de modo a responsabilizar o produtor pela qualidade de seu produto e serviço. "Em relação à vigilância sanitária, o Código reforçou a legislação específica de proteção e defesa da saúde" (BUENO; TAITELBAUM, 2008, p. 133). Seis anos mais tarde, no governo de Fernando Henrique Cardoso, uma lei originada dentro da SNVS, a lei de no 9.294 (BRASIL, 1996), aponta relevantes novidades para a propaganda de cigarros, bebidas alcoólicas e medicamentos.

\section{A virada do milênio e a criação da ANVISA}

$\mathrm{Na}$ década de 90, o Brasil passou por um processo drástico de reformas do aparelho do Estado, promovido pelo governo de Fernando Collor. Em 1992, a possibilidade de reestruturação da SNVS fica cada vez mais próxima da realidade. Segundo Lucchese, tal situação é impulsionada pelo "discurso inovador da época, que aspirava à modernidade administrativa por meio da redução do tamanho do Estado, d a desregulamentação, da privatização e da extinção dos órgãos e empresas públicas" (2008, p. 103). No entanto, até o final dos anos 90, a SNVS tem um período conturbado, e somente em 1998 foi transformada em uma agência autônoma pela Lei no 9.782 (BRASIL, 1999). 


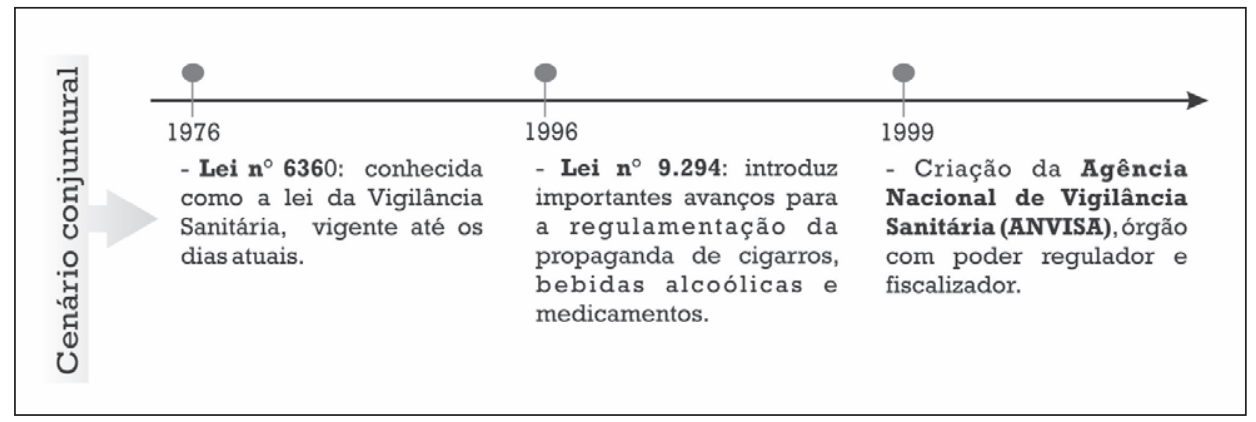

Ainda que a atuação do órgão seja alvo de críticas, pode-se dizer que somente com a criação da Agência Nacional de Vigilância Sanitária (ANVISA) instalamse mecanismos efetivos em busca de regulamentar e fiscalizar a propaganda de medicamentos, uma vez que o órgão de natureza federal concentrou esforços de diversos outros que atuavam de forma isolada, alterando "o arranjo de vigilância sanitária no país" (LUCCHESE, 2008, p. 103).

Ao ser criada, a ANVISA incorporou as competências da extinta Secretaria Nacional de Vigilância Sanitária do Ministério da Saúde (SNVS/MS), além de outras, como: a coordenação do Sistema Nacional de Vigilância Sanitária (SNVS); a execução do Programa Nacional de Sangue e Hemoderivados e do Programa Nacional de Prevenção e Controle de Infecções Hospitalares; o monitoramento de preços de medicamentos e de produtos para a saúde e a aplicação de penalidades por concorrência desleal ou preços excessivos (PAULA, 2010, p. 20)

Como missão principal, a agência destaca a proteção e a promoção da saúde da população, de modo a garantir a segurança sanitária de produtos e serviços ${ }^{1}$. Um ano depois de sua criação, em 2000, uma proposta de regulamentação, submetida à consulta pública, foi aprovada pela Diretoria Colegiada do órgão, consolidando-se na RDC 102 (BRASIL, 2000).

Esse controle é eticamente defensável, uma vez que, em questões básicas como a saúde pública, o Estado deve tomar a frente e intervir, no compromisso de proteger a população contra qualquer possibilidade de ação que venha causar-lhe dano (FAGUNDES et al, 2007, p. 222).

A RDC se torna um importante instrumento no controle da promoção e da divulgação de medicamentos de produção nacional ou importados. No mesmo ano, é implantada a Gerência de Fiscalização e Controle de Medicamentos e 
Produtos (GFIMP) da ANVISA, com o papel de fiscalizar a propaganda de produtos sujeitos à vigilância sanitária.

Dois anos mais tarde, a GFIMP cria o Projeto de Monitoração da Propaganda de Medicamentos, desenvolvido em parceria com as universidades públicas federais, descentralizando, então, a atividade de controle dos anúncios de produtos relacionados à saúde. Em 2004, a GFIMP cede lugar a Gerência de Fiscalização e Monitoração de Propaganda, Publicidade, Promoção e Informação de Produtos Sujeitos à Vigilância Sanitária (GPROP), criada pela Portaria no 123 (BRASIL, 2004), de 9 de fevereiro,

com o objetivo de coibir a disseminação de informações enganosas e abusivas que possam colocar em risco a saúde da população, além de promover a conscientização dos cidadãos e dos profissionais de saúde em relação ao uso racional dos produtos sujeitos à vigilância sanitária (BOCHNER, 2005, p. 59).

\section{RDC 96/2008: o que mudou?}

Em 2008, a agência implanta uma nova regulação: a RDC 96 (BRASIL, 2008), elaborada com base nos resultados do Projeto de Monitoração, que até então se apoiava na RDC 102/2000. Ao analisar tal projeto, Nascimento (2007) demonstrou que o descumprimento à resolução apresentava índices alarmantes.

A maior quantidade de infrações registradas $(20,5 \%)$ diz respeito à não citação obrigatória da contra-indicação principal do produto anunciado, seguida da ausência de registro do produto $(15,3 \%)$, sugestão da ausência de efeitos adversos $(10,2 \%)$, mensagens de que o produto fora "aprovado" ou "recomendado" por especialistas $(10 \%)$, sugestão de menor risco (9\%) ou a peça publicitária realizava comparações sem embasamento científico $(8,8 \%)$ (NASCIMENTO, 2007, p. 872).

Além disso, a própria legislação apresentava diversas fragilidades, o que desencadeou um processo de consultas públicas para propor uma nova regulamentação. Ao longo desse período, entre 2000 e 2008, outras duas legislações também tiveram um papel importante, conforme apontado por Bochner (2005): a RDC 133 (BRASIL, 2001) e a RDC 199 (BRASIL, 2004) alteraram pontos na RDC 102 relativos à promoção de medicamentos nos estabelecimentos farmacêuticos. Um episódio de grande repercussão para a época foi a Consulta Pública 84/2005, que objetivava propor uma reformulação do modelo de regulação do setor. A consulta gerou polêmica ao ser paralisada pela ANVISA, que, segundo Nascimento, cedeu à pressão do setor regulado. 
É nesse cenário que se implementa a RDC 96, ainda vigente, em que já não há mais a atuação do projeto que monitorava a promoção comercial em parceria com as instituiçōes federais de ensino superior. Por mais que houvesse um intenso debate, pequeno parece ter sido o impacto das mudanças trazidas pela atual resolução.

Observando as principais alterações trazidas pela nova resolução, nota-se que há poucas mudanças ao setor regulado. $\mathrm{O}$ texto tornou-se mais extenso e um pouco mais detalhado. As definições adotadas no âmbito do regulamento foram ampliadas (PAULA, 2010, p. 85).

A Tabela 2 traça um comparativo, expondo as principais alterações da RDC de 2008 em relação à de oito anos anteriores.

Tabela 2. Comparativo entre as RDCs 102/00 e 96/08.

\begin{tabular}{|l|l|l|}
\hline \multicolumn{1}{|c|}{ Assunto } & \multicolumn{1}{|c|}{ RDC 102/2000 } & \multicolumn{1}{c|}{ RDC 96/2008 } \\
\hline $\begin{array}{l}\text { Mensagem de alerta } \\
\text { ao consumidor }\end{array}$ & $\begin{array}{l}\text { Toda propaganda deve conter } \\
\text { a frase: "AO PERSISTIREM } \\
\text { OS SINTOMAS, O MÉDICO } \\
\text { DEVERÁ SER CONSULTADO". }\end{array}$ & $\begin{array}{l}\text { Inclui advertências relativas aos } \\
\text { princípios ativos. A frase de alerta } \\
\text { da RDC 102 permanece como } \\
\text { requisito básico e obrigatório. }\end{array}$ \\
\hline $\begin{array}{l}\text { Presença de } \\
\text { celebridades }\end{array}$ & Não há menção. & $\begin{array}{l}\text { Restringe a participação de pessoas } \\
\text { famosas, estabelecendo que não } \\
\text { podem dizer frases imperativas, } \\
\text { como: "experimente", "tome" ou } \\
\text { "comprove". }\end{array}$ \\
\hline $\begin{array}{l}\text { Merchandising } \\
\text { (ou publicidade } \\
\text { subjetiva, difundida } \\
\text { de modo indireto) }\end{array}$ & $\begin{array}{l}\text { Sujeita às mesmas restrições de } \\
\text { propaganda. }\end{array}$ & $\begin{array}{l}\text { Fica proibido qualquer tipo de } \\
\text { divulgação que seja feita de modo } \\
\text { não declaradamente publicitário. }\end{array}$ \\
\hline $\begin{array}{l}\text { Expressões } \\
\text { categóricas }\end{array}$ & $\begin{array}{l}\text { Restringe o uso de expressões } \\
\text { (como "seguro, "eficaz", } \\
\text { "totalmente natural") que sugerem } \\
\text { ausência de efeitos colaterais, } \\
\text { estando sujeito a sanções punitivas. }\end{array}$ & $\begin{array}{l}\text { Proíbe o uso dessas expressões, } \\
\text { exceto nos casos em que sejam } \\
\text { complementadas por frases que } \\
\text { justifiquem a veracidade da } \\
\text { informação. }\end{array}$ \\
\hline $\begin{array}{l}\text { Brindes e amostras } \\
\text { grátis }\end{array}$ & $\begin{array}{l}\text { Autoriza a distribuição de } \\
\text { amostras grátis, desde que não } \\
\text { exceda 50\% do conteúdo da } \\
\text { embalagem original. }\end{array}$ & $\begin{array}{l}\text { Proíbe a distribuição de brindes, } \\
\text { seja destinado ao profissional de } \\
\text { saúde ou ao público em geral; } \\
\text { veda a distribuição de amostras } \\
\text { grátis de medicamentos isentos de } \\
\text { prescrição. }\end{array}$ \\
\hline
\end{tabular}


Mesmo com essa preocupação em controlar a publicidade de medicamentos, o índice de infração à legislação é alto e preocupante, sendo constatado, por exemplo, que $20 \%$ das peças publicitárias não apresentavam a contraindicação principal do produto (NASCIMENTO, 2007, p. 174). É claro que o problema não é a falta de regulamentação, já que o decreto no 79.094 e a Lei no 6.360 demonstram que

o enfrentamento da questão da regulação do mercado farmacêutico (e em seu interior a questão da propaganda) por parte do poder público, ao contrário do que é permanentemente verbalizado por representantes da Agência Nacional de Vigilância Sanitária (ANVISA), não foi iniciado no ano de 2000 (NASCIMENTO, 2005, p. 45).

Tal fato revela que simplesmente $o$ ato de regulamentar não garante $o$ cumprimento do que está preconizado na legislação. É claro que a carência de mecanismos efetivos de fiscalização, controle e punição tem uma forte influência. Um exemplo reside no fato de as multas para os laboratórios que descumprem a lei serem tão irrisórias que acabam por estimular as irregularidades (NASCIMENTO, 2007). No entanto, não é demasiado afirmar que o único instrumento capaz de efetivar um real controle sobre a qualidade da informação disseminada nas peças publicitárias de medicamentos no Brasil é a anuência prévia. Ao estudar as experiências reguladoras internacionais, Álvaro Nascimento mostrou que diversos países - dentre os quais estão Austrália, México e alguns países da Europa - adotaram a anuência prévia como uma medida base desse processo, pois, afinal, só assim pode-se tentar impedir a exposição da população ao risco sanitário. No caso europeu, a diretiva reguladora 2001/83, no artigo 87, determina que os Estados-Membros devem proibir anúncios para os quais não tenha sido concedida uma autorização de introdução no mercado (NASCIMENTO, 2007, p. 139).

No Brasil, embora tenha recebido grande apoio por parte dos representantes da sociedade civil, a anuência prévia acabou sendo rejeitada, prevalecendo a posição do setor regulado de que seria um ato inconstitucional, contra à liberdade de imprensa. A realidade internacional mostra, entretanto, que essa é a saída para evitar estratégias abusivas na promoção de produtos farmacêuticos. Com base no pequeno percurso abordado neste estudo, pode-se entender que a questão da regulação sanitária nacional é de natureza mais estrutural, ligada a um sistema complexo e remoto. 


\section{Considerações finais}

A questão da propaganda de medicamentos vem se tornando uma preocupação de saúde pública, já que implica em risco à população. Isso é tão sério que Barros chega a afirmar que a promoção comercial tem ajudado "a despolitizar a compreensão do processo saúde/doença e da sua determinação social” (BARROS, 2004, p. 53). Tal problemática engloba diferentes atores e permeia diversas questôes, que contornam o campo. Entre estratégias e discursos, destacam-se as concernentes à indústria farmacêutica e ao Estado. Os embates entre eles não são novos. Ao contrário, vêm sendo travados desde as primeiras tentativas por parte do governo de regulamentar a promoção comercial dos produtos com finalidades terapêuticas.

Sendo assim, entender a formação da sociedade brasileira desde o Império se faz fundamental para uma análise mais contundente da realidade hoje. Nesse contexto, encontra-se certa complexidade para definir os interesses de ambas as partes. $\mathrm{O}$ fardo do Brasil colônia parece contribuir com isso, à medida que deixa a herança da falta de autonomia da nação e da dificuldade de definição dos papéis. Em diversos momentos da história recente do país, fica fácil de notar que o próprio governo fica confuso quanto a sua atuação. Um momento que pode elucidar tal afirmação é durante a reforma proposta pelo governo Collor. Lucchese é categórico ao afirmar que "uma das principais críticas aos pressupostos da reforma do Estado questiona o objetivo de atingir-se maior eficiência do Estado apenas com a mudança da administração burocrática, sem efetuar mudanças no sistema político" (2008, p. 102). Por mais que a reforma da SNVS acontecesse a partir de uma demanda natural da época, ela acabou por reafirmar, nesse tempo de desregulamentação e privatização, a diluição das fronteiras entre o domínio público e privado.

A perspectiva histórica mostra que, desde os tempos da República, existiam iniciativas voltadas para a regulação e controle sanitário, mas essas se davam de maneira dispersa, não havendo um órgão capaz de concentrar esses esforços. A ANVISA representou a oportunidade de confluência dessas ações, que antes não se comunicavam. No entanto, assim como todos os marcos apontados, a agência reguladora é reflexo do contexto da vigilância sanitária no Brasil. Assim, não fica isenta dos problemas de natureza estrutural. Uma forte crítica ao órgão reside na sua gradativa mudança de diretriz. Ao analisar a ANVISA, a pesquisadora Paula 
342 demonstrou que o Projeto de Monitoração de Propaganda de Produtos Sujeitos à Vigilância Sanitária não mais atuava no monitoramento e na fiscalização de peças infratoras, e sim em ações de educação continuada. Dessa forma, cada vez mais, a agência perde seu papel fiscalizador e regulatório para investir em ações de educação e informação para a sociedade. Além disso, a RDC 96/2008 representou pequeno avanço para a regulamentação sanitária, embora a própria ANVISA tenha reconhecido diversas irregularidades.

A promoção comercial de medicamentos e de outros produtos para a saúde tem, hoje, uma dimensão que parece ser peculiar a toda sua trajetória antecedente. Um novo ator entra em cena: a população. Se antes poderia dizer-se que a sociedade era carente de informação, nos tempos atuais, o cidadão se torna cada vez mais ciente dos seus direitos, especialmente quando se relacionam à sua saúde.

No entanto, ainda assim, a sociedade civil, de modo geral, acaba sendo a grande prejudicada diante do quadro que se delineia. Afinal, ao buscar simplesmente informar e educar, deixando de lado suas atividades primárias, o governo transmite a responsabilidade para o consumidor e se isenta de qualquer tipo de culpa. Sem o controle devido, os laboratórios continuam a utilizar de mecanismos intensos de comunicação e marketing, contribuindo para o consumo indiscriminado de drogas lícitas.

A partir dessas considerações, evidencia-se a necessidade de estimular o debate nas instâncias públicas e midiáticas, de modo a propiciar a participação da sociedade, que, em muitas circunstâncias, por desconhecer as questões do campo, torna-se ainda mais vulnerável às estratégias da indústria de medicamentos. Nesse sentido, somente com o respaldo social, será possível preconizar novos rumos para a regulação sanitária ${ }^{1}$.

\section{Referências}

ANGELL, M. A verdade sobre os laboratórios farmacêuticos. Rio de Janeiro: Record, 2009. 319 p. BARROS, J.A.C.de. Politicas farmacêuticas: a serviço dos interesses da saúde? Brasília: UNESCO, 2004. $270 \mathrm{p}$.

Propaganda de medicamentos. Atentado à saúde? São Paulo: Hucitec, 1995. 289 p.

BOCHNER, R. Papel da Vigilância Sanitária na prevenção de intoxicações na infância. Revisa, n. 1, v. 1, p. 50-57, 2005. 
BRASIL. ANVISA. Análise do Consolidado de propostas encaminhadas durante a Consulta

84/2005. 2009a. Disponível em: <http:www.anvisa.gov.br/DIVULGA/noticias/2007/ 111207_2_anexo2.pdf> Acesso em: 10 abr 2010.

. Portaria n. 123, de 09 de fevereiro de 2004. Disponível em: <http://elegis.anvisa. gov.br/leisref/public/showAct.php?id=9795\&mode=PRINT_VERSION >. Acesso em: 03/09/2010.

. Resolução no. 102, de 30 de novembro de 2000. Disponível em: <http://www. anvisa.gov.br/legis/resol/2000/102_00rdc.htm>. Acesso em: 03/09/2010.

. Resolução no. 133, de 12 de julho de 2001. Disponível em: <http://www.anvisa. gov.br/Legis/resol/133_01rdc.htm>. Acesso em: 06/08/2011.

. Resolução no. 96, de 17 de dezembro de 2008. Disponível em: <http://www. anvisa.gov.br/propaganda/rdc/rdc_96_2008_consolidada.pdf>. Acesso em: 03/09/2010.

. Resolução nº 99, de 06 de maio de 2004. Disponível em: <http://elegis.anvisa. gov.br/leisref/public/showAct.php?id=11005\&mode=PRINT_VERSION >. Acesso em: 06/08/2011.

BRASIL. Código de Ética publicitária, outubro de 1957. Define os princípios éticos que devem nortear a publicidade. Associação Brasileira de Agências de Publicidade - ABAP, São Paulo, SP. Disponível em: <http://www.abapnacional.com.br/pdfs/leis/codigo_de_etica_ profissional.pdf $>$. Acesso em: 18/01/2011.

. Decreto n. 68.806, de 25 de junho de 1971. Institui a Central de Medicamentos (CEME). Diário Oficial [da] República Federativa do Brasil, Poder Executivo, Brasília, DF. 25 jun. 1971. Seção 1, p. 4839.

Decreto n. 72.552, de 14 de setembro de 1973. Dispõe sobre as Políticas e Diretrizes Gerais do Plano Diretor de Medicamentos e dá outros providências. Diário Oficial [da] República Federativa do Brasil, Poder Executivo, Brasília, DF. 18 set. 1973. Seção 1, p. 9346.

. Decreto $n^{\circ}$. 79.094, de 05 de janeiro de 1977. Regulamenta a Lei no 6.360, de 23 de setembro de 1976, que submete a sistema de vigilância sanitária os medicamentos, insumos farmacêuticos, drogas, correlatos, cosméticos, produtos de higiene, saneantes e outros. Diário Oficial [da] República Federativa do Brasil, Poder Executivo, Brasília, DF. 07 jan. 1977. Seção 1, p. 11.

. Decreto-lei no. 16.300, de 31 de dezembro de 1923. Aprova o regulamento do Departamento Nacional de Saúde Pública. Diário Oficial [da] República Federativa do Brasil, Poder Executivo, Brasília, DF, 01 fev. 1924. Seção 1, p. 3199.

. Decreto-lei nº. 20.377, de 8 de setembro de 1931. Resolve aprovar o regulamento anexo para o exercício da profissão farmacêutica no Brasil. Conselho Federal de Química. Brasília, DF. Disponível em: <http://www.cfq.org.br/d20377.htm>. Acesso em: 20/11/2010. 
. Decreto-lei n ${ }^{\circ}$. 21.111, de 1 de março de 1932. Aprova o regulamento para a execução dos serviços de radiocomunicação no território nacional. Diário Oficial [da] República Federativa do Brasil, Poder Executivo, Brasília, DF, 04 mar. 1932. Seção 1, p. 3914.

Decreto-lei $n^{\circ}$. 4.113, de 14 de fevereiro de 1942. Regula a propaganda de médicos, cirurgiões dentistas, parteiras, massagistas, enfermeiros, de casas de saúde e de estabelecimentos congêneres, e a de preparados farmacêuticos. Diário Oficial [da] República Federativa do Brasil, Poder Executivo, Brasília, DF. 18 fev. 1942. Seção 1, p. 2443.

Lei nº 6.360, de 23 de setembro de 1976. Lei de Vigilância Sanitária. Dispõe sobre a vigilância sanitária a que ficam sujeitos os medicamentos, as drogas, os insumos farmacêuticos e correlatos, cosméticos, saneantes e outros produtos, e dá outras providências. Diário Oficial [da] República Federativa do Brasil, Poder Executivo, Brasília, DF. 24 set. 1976. Seção 1, p. 12647.

Lei n. 8.078, de 11 de setembro de 1990. Código de Defesa do Consumidor. Disponível em: <http://www.planalto.gov.br/ccivil_03/leis/18078.htm >. Acesso em: 05/02/2011.

Lei n. 9.294, de 15 de julho de 1996. Dispóe sobre as restrições ao uso e à propaganda de produtos fumígeros, bebidas alcoólicas, medicamentos, terapias e defensivos agrícolas, nos termos do $\$ 4^{\circ}$ do art. 220 da Constituição Federal. Diário Oficial [da] República Federativa do Brasil, Poder Executivo, Brasília, DF. 16 jul. 1996. Seção 1, p. 13064.

. Lei nº 9.782, de 26 de janeiro de 1999. Define o Sistema Nacional de Vigilância Sanitária, cria a Agência Nacional de Vigilância Sanitária, e dá outras providências. Diário Oficial [da] República Federativa do Brasil, Poder Executivo, Brasília, DF. 11 fev. 1999. Seção 1, p. 1.

BUENO, E.; TAITELBAUM, P. Vendendo Saúde - A história da propaganda de medicamentos no Brasil. Brasília: ANVISA, 2008. 159 p.

FAGUNDES, M.J.D. Análise bioética da propaganda e publicidade de medicamentos. Ciência e Saúde Coletiva, n.1, p.221-229, jan.-mar. 2007.

KOTLER, P.; KELLER, K.L. Administração de marketing. 12ed. São Paulo: Pearson Prentice Hall, 2006. 776 p.

LUCCHESE, G. Globalização e regulação sanitária. Brasília: Anvisa, 2008. 353 p.

NASCIMENTO, A.C. "Ao persistirem os sintomas, o médico deverá ser consultado". Isto é regulação? São Paulo: Sobravime, 2005. 151 p.

. Propaganda de medicamentos no Brasil. É possivel regular? Ciência e Saúde Coletiva, n.14, v.3, p.869-877, 2009.

. Propaganda de medicamentos. É possível regular? 2007. 289 f. Tese (Doutorado em Saúde Coletiva) - Instituto de Medicina Social, Universidade Estadual do Rio de Janeiro. 
NASCIMENTO, M.C.do. Medicamentos: ameaça ou apoio à saúde? Rio de Janeiro: Vieira e Lent, 2003. 197 p.

PAULA, F.A.de. Análise das açôes do órgão regulador da propaganda de medicamentos no Brasil no periodo de 2005 a 2009. 2010. 127 p. Dissertação (Mestrado em Saúde Coletiva) Escola Nacional de Saúde Pública, Fundação Oswaldo Cruz, Rio de Janeiro, 2010.

ROZENFELD, S. Farmacovigilância: elementos para a discussão e perspectivas. Ciência e Saúde Coletiva, n.14, v.2, p.237-263, abr.-jun. 1998.

TEMPORÃO, J.G. A propaganda de medicamentos e o mito da saúde. Rio de Janeiro: Graal, 1986. $183 \mathrm{p}$.

\section{Nota}

${ }^{1}$ C.P. Araújo participou da redação do artigo, coleta e análise de dados; R. Bochner participou da coleta e análise de dados; A. Nascimento participou da coleta e análise de dados. 


\section{Legal frameworks of drug advertisement: progress and setbacks}

Since the beginning of Brazilian civilization, there is already disclosure of pharmaceutical drugs being the favorite of the ads. The advertising of medicines, while persuasive strategy, may represent health risk, if not compromised with the release of accurate and safe information. For that reason, there are several attempts at sanitary control by the state, which appears to be consolidated in the struggles of the ethical and legal domain. In seeking to understand the context that guides, the current situation of the drug advertising problem, this study provides a historical background, from the main legal frameworks: "Junta Central de Higiene" (1851), "Lei de Vigilância Sanitária" (1976) and the creation of "ANVISA" (1999). It was identified that milestone follows the country structural context, contributing to the consolidation of the regulation's field nowadays.

Key words: drug publicity; health surveillance; history. 